Military Technical College Kobry El-Kobbah, Cairo, Egypt

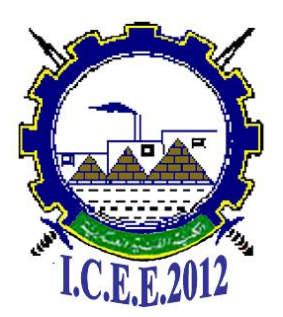

$6^{\text {th }}$ International Conference

on

Chemical \& Environmental

Engineering

29 -31 May, 2012.

\title{
ENMC-1
}

\section{TAYLOR'S THEORY VERIFICATION OF THE RELATIVE STRENGTH MEASUREMENT USING BALLISTIC MORTAR}

\begin{abstract}
This article is focused on exploration of a ballistic mortar measurement process. Ballistic mortar swing serves for determination of relative explosive strength of explosives and propellants in a common practice. However, the amount of energy exploited as the mortar swing is surprisingly low in contrast with kinetic energy of the projectile and the whole energy of explosion. Projectile velocity can thus be more accurate measure corresponding to the real explosive energy. The article contains results of our initial measurements in this field.
\end{abstract}

Künzel, M.; Němec, O.; Musil, T.;Zeman, S.

Institute of Energetic Materials, Faculty of Chemical Technology,University of Pardubice, CZ-53210 Pardubice, Czech Republic

E-mail: nemi.ondra@seznam.cz 


\section{Introduction}

Relative explosive strength (RS) is one of basic characteristics of energetic materials. In general, RS represents amount of energy that is free for transforming to work. It is well known, that RS depends on heat of detonation and volume of detonation gases. It is assumed that RS does not depend on homogeneity and density (Sućeska 1995) of the given explosive. This assumption is questioned in our earlier work (Němec 2012).

RS is most often measured by two tests - ballistic mortar test and Trauzl block test. In Institute of Energetic Materials we are using ballistic mortar test for determination of RS. Ballistic mortar test is well known and very precise test. Published results can be found since forties of the 20th century (Taylor 1932). In the work (Taylor 1949) authors measured RS of $10 \mathrm{~g}$ of TNT charges with error lower than $1 \%$. In our earlier work (Němec 2012) we measured RS with error smaller than $2 \%$ in case of mixed explosives based on ammonium and calcium nitrate emulsion matrix with TNT in the ratio 50:50. Ballistic mortar test is based on the principle of measuring pendulum deflection angle which is caused by explosion of the sample in explosion chamber closed with steel projectile inserted in projectile chamber. Ballistic pendulum, ballistic mortar and projectile are shown in figures $1-3$.

The whole system resembles a short barrel gun. After initiation of the sample projectile is shot away and ballistic pendulum deflects. According to (Taylor 1932) the deflection of ballistic pendulum and velocity of projectile should be linearly dependent as it is described by equation 1. The same work argues that bulk of the energy is vested in the projectile on account of its smaller mass.

$v=\sqrt{\frac{W S J g(1-\cos \alpha)}{m^{2} r^{2}}}$

Equation 1

Where $v$ is velocity of projectile, $W$ is total mass of pendulum system, $S$ is depth of centroid below axis of suspension, $J$ is moment of inertia about the axis of suspension, $g$ is gravitational acceleration, $\alpha$ is angle of pendulum deflection, $r$ is depth of axis of firing chamber below axis of suspension and $m$ is projectile mass. Until now nobody had verified theoretical assumption (Taylor 1932) that pendulum deflection and velocity of projectile are linearly dependent at ballistic mortar experiments.

\section{Experimental}

As a reference we used military grade trinitrotoluene (TNT), which was melted and molded to the shape of cylindrical charges with variable weight. Ballistic mortar was then calibrated using these charges while pendulum deflection and velocity of projectile were measured. The first calibration equation was $y=41.924 x+399.72$, where $y$ is pendulum deflection and $x$ is charge weight, regression coefficient $R^{2}=0.9948$. The second calibration curve was made from velocity of projectile giving regression equation $v=1.8759 x+18.29$ where $v$ is projectile velocity, regression coefficient $R^{2}=0.9917$. Samples of erythritol tetranitrate (ETN), RDX + 9\% wax (A-IX-1), TNT + ammonium nitrate (AN) in 50/50 ratio (amatol) and 2,4-dinitrotoluene (DNT) were then measured. All samples were initiated by nonelectric detonator (no. 8, Sellier \& Bellot Corp.). Description of samples and measured data are shown in Table 1.

Velocity of the projectile was measured using Canon EOS 550D digital single lens reflex camera equipped with Canon EF-S 18-135 IS lens. Movies were taken for all samples at the frame rate of 60 frames per second with resolution of $1280 \times 720$ pixels. For each sample, all frames where projectile appeared were extracted from the movie and distance travelled by the 
projectile was measured in pixels of original image. Conversion of pixels to meters was accomplished using known length of flight trajectory between the mortar and the landing pit. Time of flight between desired frames was calculated from the frame rate. Example of the measurement evaluation is shown in Figure 4.

Relationship between pendulum deflection and velocity of projectile is shown in Figure 5. It is clear, that theoretical assumptions of the work (Taylor 1932) are right and ballistic mortar can be calibrated on the basis of pendulum deflection as well as velocity of projectile, giving nearly the same values of RS. This study shows that pure DNT has RS value around $68 \%$ of TNT.

\section{Conclusion}

The amount of energy exploited as the mortar swing is surprisingly low in contrast with kinetic energy of the projectile and the whole energy of explosion. Projectile velocity can thus be more accurate measure corresponding to the real explosive energy. However, our results show that ballistic mortar can be calibrated on the basis of pendulum deflection as well as velocity of projectile, giving nearly the same values of RS. Very tight relation between both these characteristics confirms the theoretical Taylor's assumption (Taylor 1932) of this linear dependence. 
Table 1. Pendulum deflections, velocity of projectile and description of samples

\begin{tabular}{|c|c|c|c|c|}
\hline Sample & $\begin{array}{l}\text { Weight of } \\
\text { sample }(g)\end{array}$ & $\begin{array}{l}\text { Pendulum } \\
\text { Deflection } \\
\quad(\mathrm{mm})\end{array}$ & $\begin{array}{l}\text { Projectile } \\
\text { velocity } \\
\left(\mathrm{ms}^{-1}\right)\end{array}$ & $\begin{array}{c}\text { Sample } \\
\text { description }\end{array}$ \\
\hline \multirow{18}{*}{ TNT } & 6,37 & 660 & 27,9 & \multirow{18}{*}{ Melt cast military grade TNT } \\
\hline & 5,88 & 640 & 28,5 & \\
\hline & 6,11 & 640 & 29,2 & \\
\hline & 8,07 & 730 & 31,7 & \\
\hline & 8,05 & 740 & 32,4 & \\
\hline & 8,03 & 735 & 31,9 & \\
\hline & 10,01 & 820 & 36,9 & \\
\hline & 10,05 & 835 & 35,9 & \\
\hline & 10,00 & 835 & 36,3 & \\
\hline & 12,08 & 920 & 40,8 & \\
\hline & 12,09 & 920 & 39,9 & \\
\hline & 12,03 & 920 & 39,7 & \\
\hline & 14,06 & 985 & 42,4 & \\
\hline & 14,00 & 990 & 43,4 & \\
\hline & 13,98 & 980 & 43,4 & \\
\hline & 15,92 & 1055 & 47,0 & \\
\hline & 16,03 & 1060 & 46,0 & \\
\hline & 15,93 & 1060 & 45,8 & \\
\hline \multirow{3}{*}{ ETN } & 10,07 & 975 & 42,3 & \multirow{3}{*}{$\begin{array}{l}\text { Melt cast ETN, prepared } \\
\text { according to (Bergeim 1928) }\end{array}$} \\
\hline & 10,07 & 975 & 42,7 & \\
\hline & 10,03 & 970 & 42,1 & \\
\hline \multirow{3}{*}{ A-IX-1 } & 10,00 & 995 & 44,2 & \multirow{3}{*}{$\begin{array}{l}\text { Pressed charges from Poličské } \\
\text { strojírny Corp. production }\end{array}$} \\
\hline & 10,00 & 1015 & 43,8 & \\
\hline & 10,00 & 1005 & 43,0 & \\
\hline \multirow{3}{*}{ Amatol } & 10,85 & 960 & 41,3 & \multirow{3}{*}{$\begin{array}{l}\text { Melt cast charges, prepared from } \\
\text { AN (Synthesia Corp.) and military } \\
\text { grade TNT. }\end{array}$} \\
\hline & 10,35 & 920 & 42,0 & \\
\hline & 10,94 & 930 & 41,5 & \\
\hline \multirow{3}{*}{ DNT } & 9,03 & 635 & 27,6 & \multirow{3}{*}{$\begin{array}{l}\text { Melt cast charges, DNT from } \\
\text { institute supply. }\end{array}$} \\
\hline & 9,43 & 670 & 29,3 & \\
\hline & 9,93 & 685 & 29,8 & \\
\hline
\end{tabular}




\section{References}

[1] Bergeim, F. H., Production of erythritol tetranitrate, Du Pont de Nemours \& Company. US1691954, 1928

[2] Němec, O., Jungová, M., Grega, J., Pelikán, V., Zeman, S., Note on determination of relative explosive strength of fortified W/O emulsions by means of ballistic mortar, Proceedings of the $15^{\text {th }}$ Int. Seminar "New Trends in Research of Energetic Materials", Univ. Pardubice, April, 2012

[3] Sućeska, M.; Test methods for Explosives, Springer-Verlag New York, 1995

[4] Taylor, J.; Cook, J. H., Operation of the ballistic mortar for determining the power of high explosives, Journal of Scientific Instruments, 26, 266-268, 1949

[5] Taylor, W.; Morris, G., The absolute measurement of the available energy of high explosives by the ballistic mortar, Transactions of the Faraday Society, 28, 545-558, 1932 


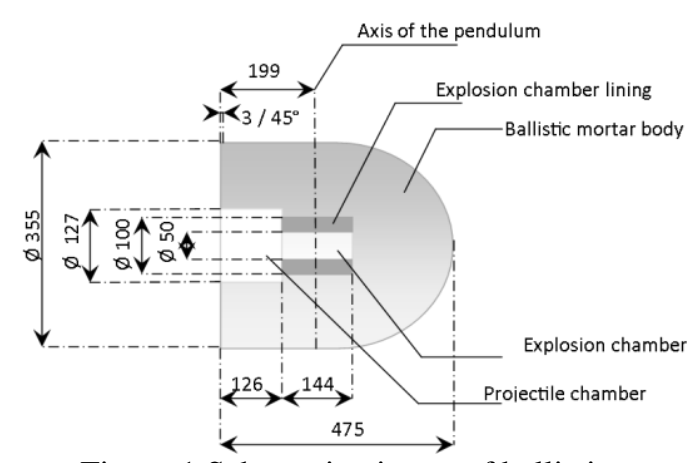

Figure 1 Schematic picture of ballistic mortar

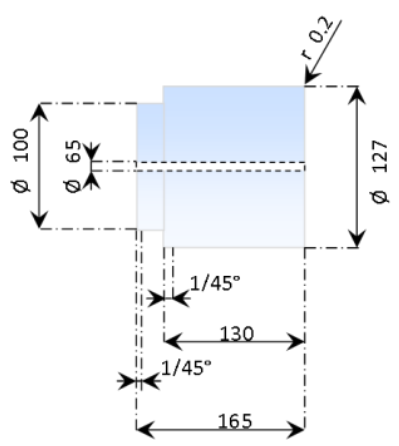

Figure 2 Schematic picture of the projectile

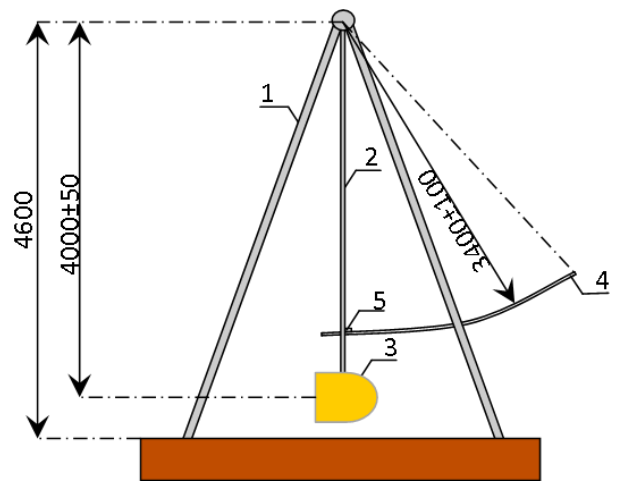

Figure 3 Schematic picture of ballistic pendulum. 1 - supporting structure, 2 - pendulum, 3 - ballistic mortar, 4 - scale, 5 - deflection recording rider
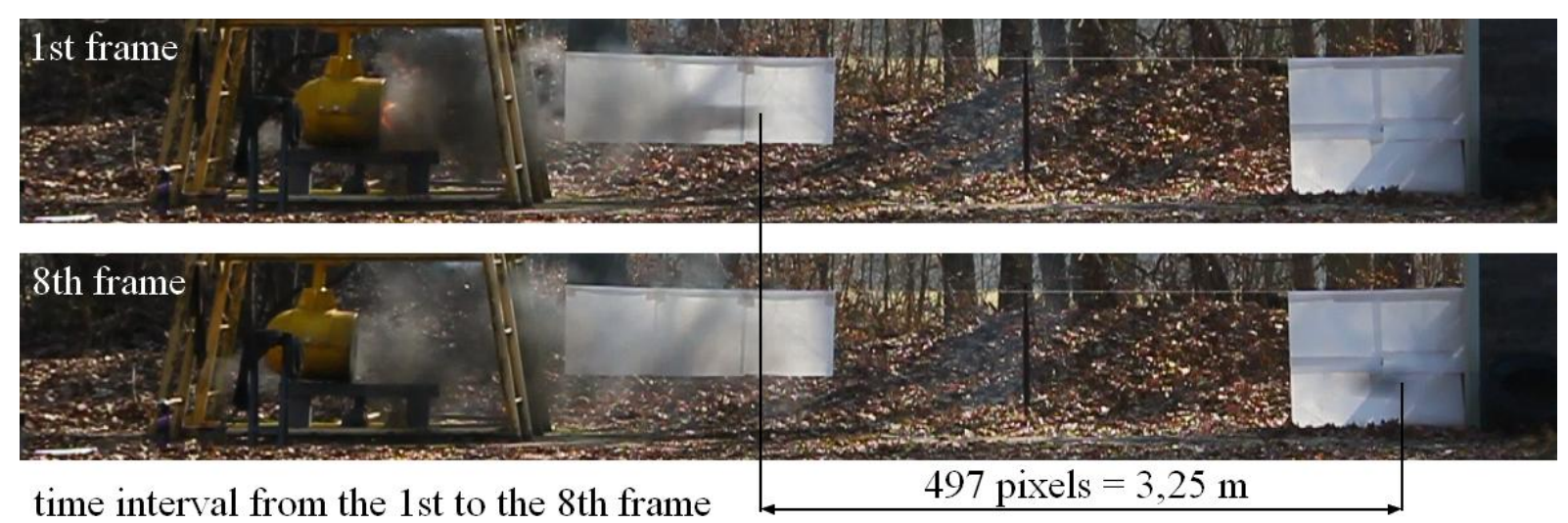

equals to $7 / 60 \mathrm{~s}$ which corresponds to the projectile velocity of $27,9 \mathrm{~m} \cdot \mathrm{s}^{-1}$

Figure 4. Example of the projectile velocity determination 


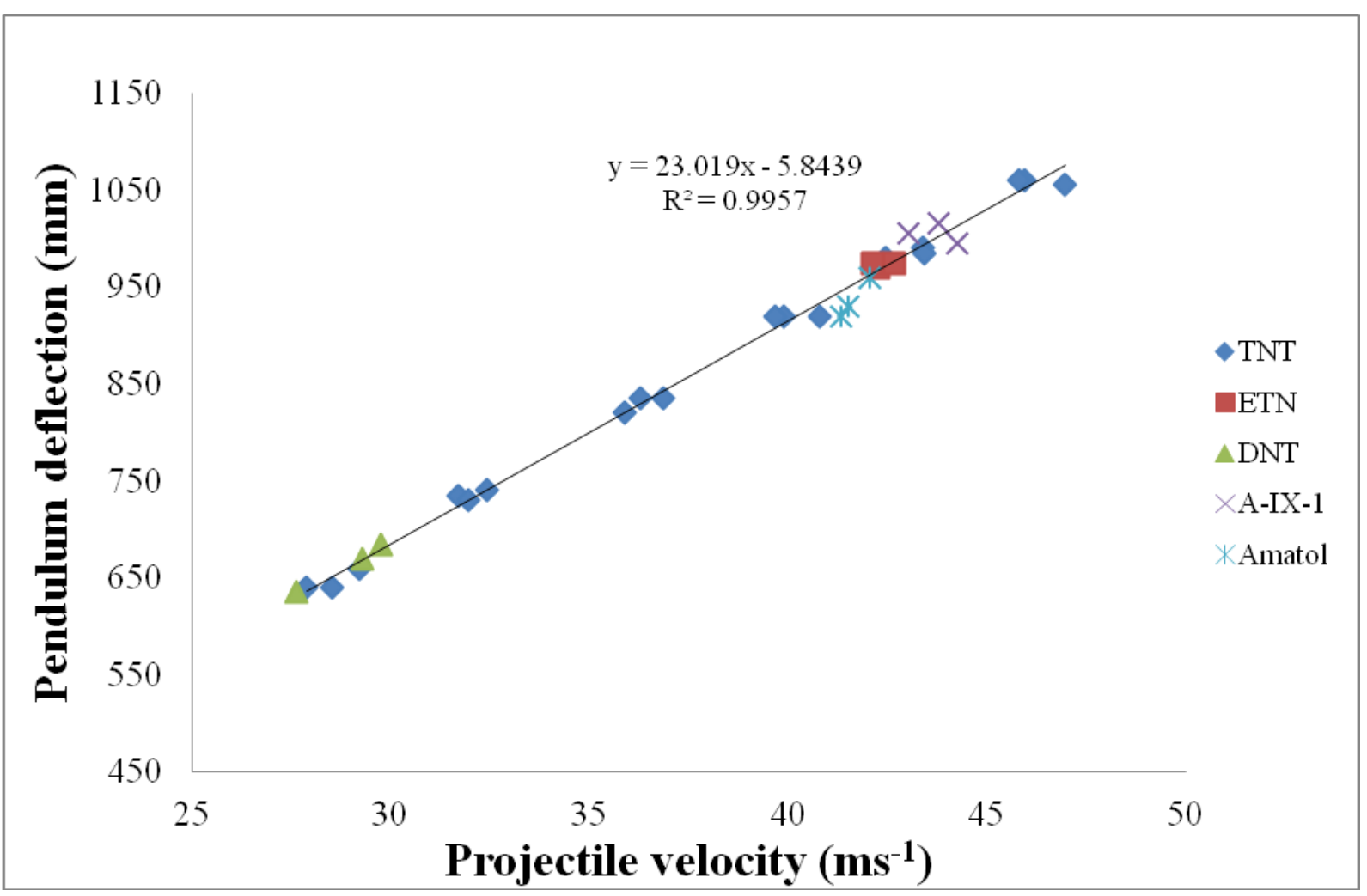

Figure 5. Dependence of pendulum deflection on projectile velocity 